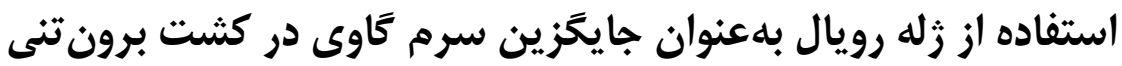

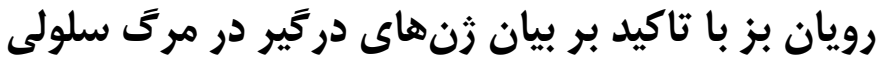

\author{
حميد دلدار \\ دانشيار گروه علوم دامى، دانشكده علوم دامى و شيلات، دانشگاه علوم كشاورزى و منابع طبيعى سارى، (نويسنده مسوول: \\ ناريخ دريافت: QV/D/TF \\ صفحه: ع V تأ
}

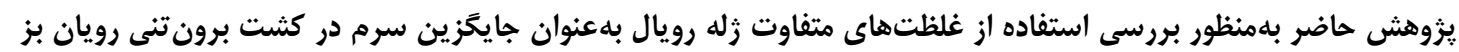

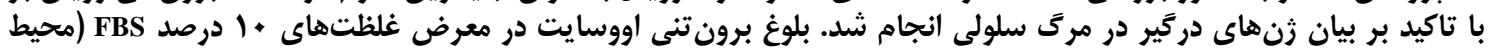

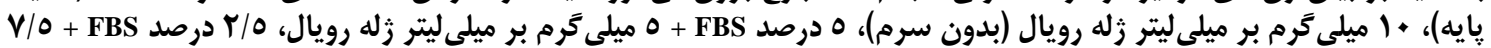
ميلى

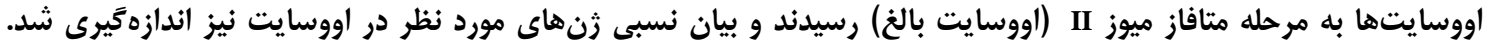

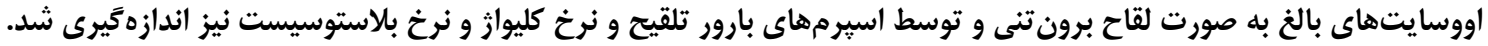

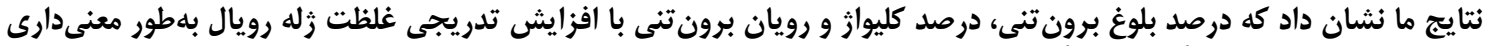

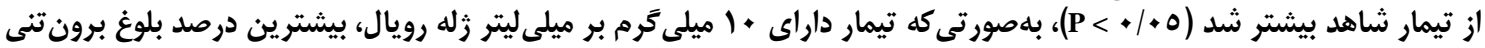

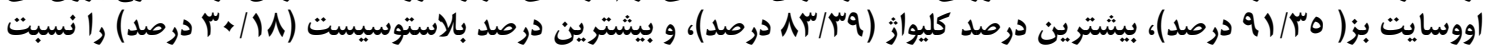

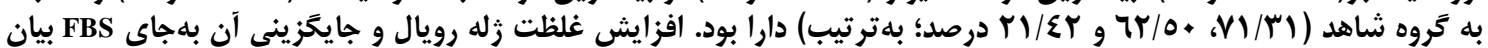

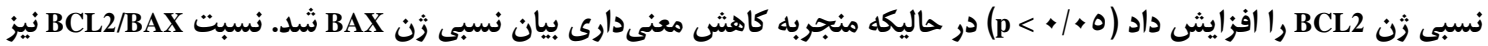

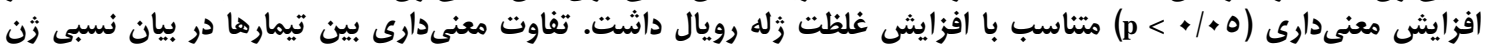
CASPASE3

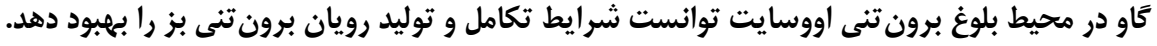

$$
\text { وازههاى كليدى: زله رويال، سرم جنين كاوى، اووسايت بز، كشت برون تنى رويان }
$$

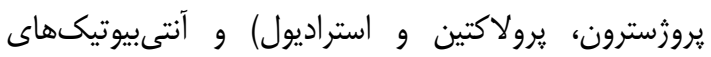

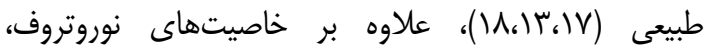

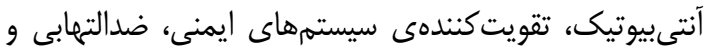

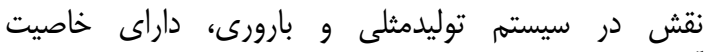

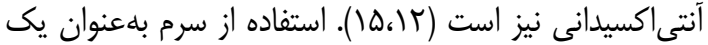

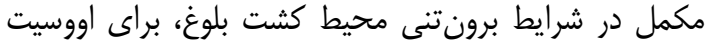

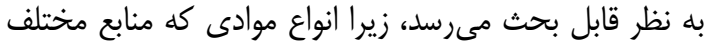

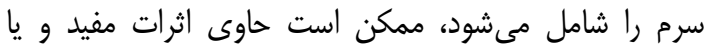

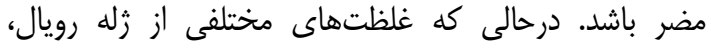

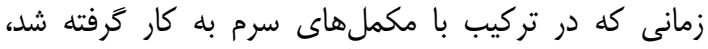

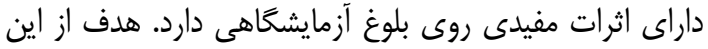

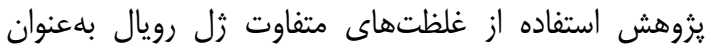

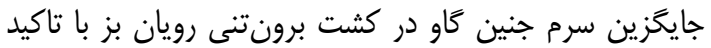

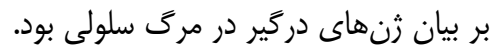

\section{مواد و روشها}

تمامى تركيبات و ورواد مواد استفاده شده از شركت سيخما

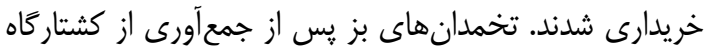

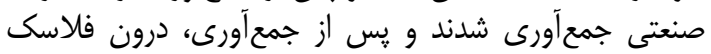

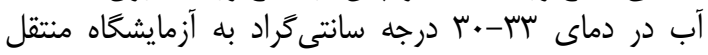

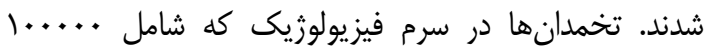

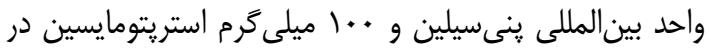

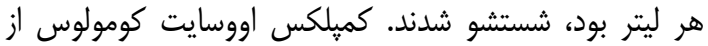

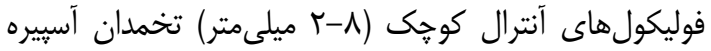

مقدمه

سرم جنين گاو (FBS) بهطور گَسترده براى محيط كشت

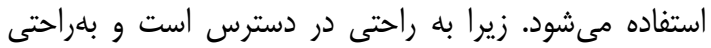

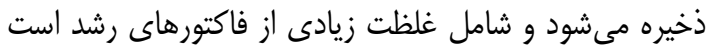

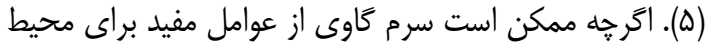

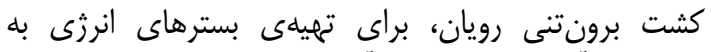

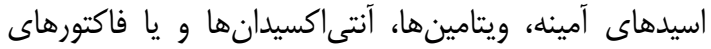
رشد باشد، ولى در عين حال ممكن است سمى نين نيز باشدا.

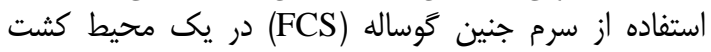

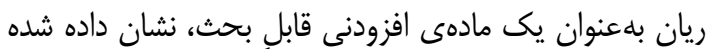

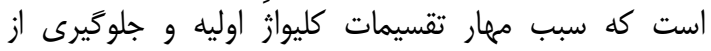

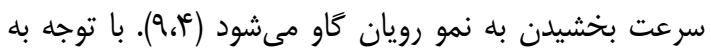

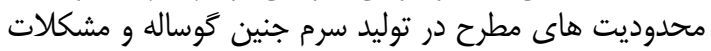

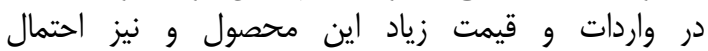

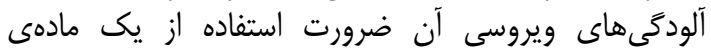

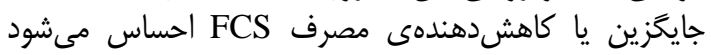

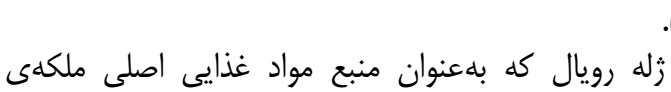

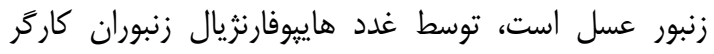
ترشح

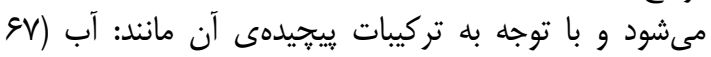

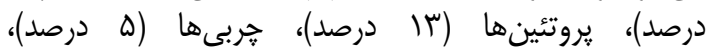

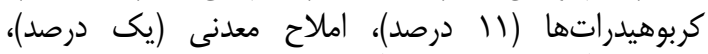
اسيدهاى آمينه، ويتامينها، آنزيمها، هورمونها، (آماح (تستوسترون، 
براى بيان نسبى زنهاى مورد نظر تا زمان انجام واكنشهاى

Real Time PCR

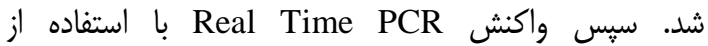

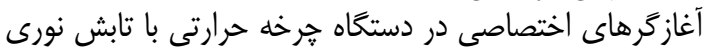

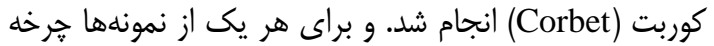

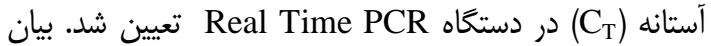

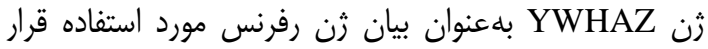

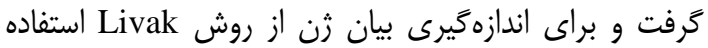
شد. يثوهش در قالب طرح كاملا تصادفى با ه تيمار و ه ت تكرار

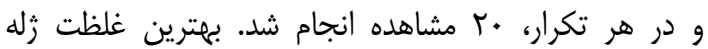

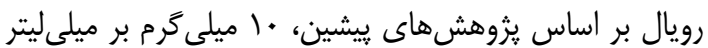

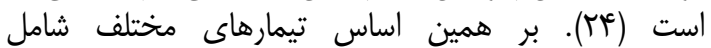

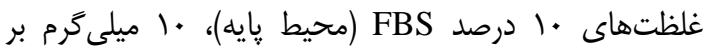

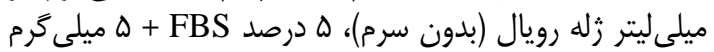

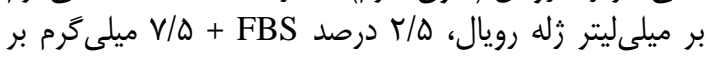

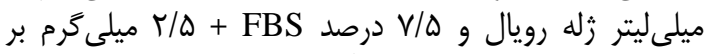

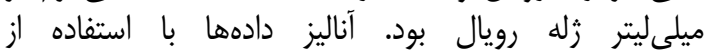

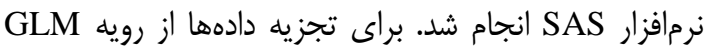

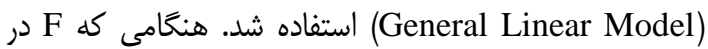
آناليز واريانس معنى دار شد، آزمون دانكن بران براى مقدئ مقايسه

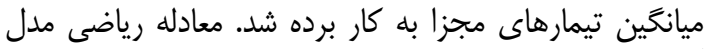

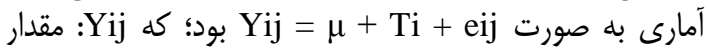

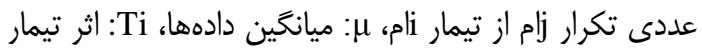
i

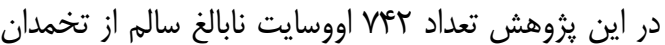

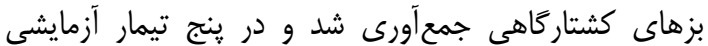

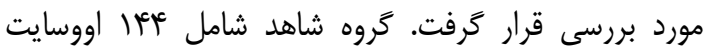

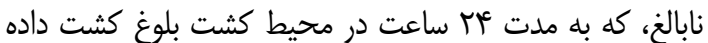

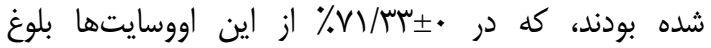

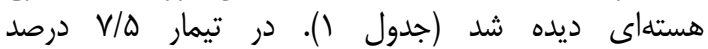
T/ + FBS

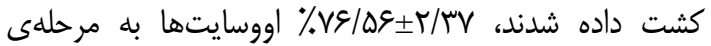

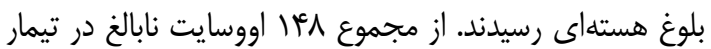

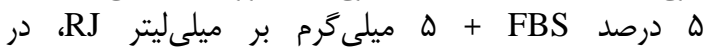

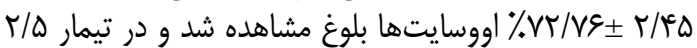
درصد VBS + FBS ميلى

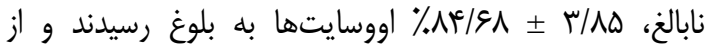

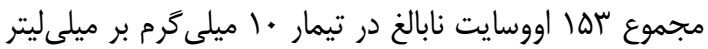

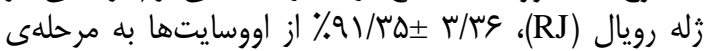

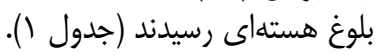

شدند و كميلكسهايى كه سه لايه كومولوس يا بيشتر و

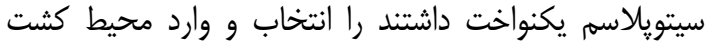
بلوغ اووسايت شدند. محيط كشت شامل

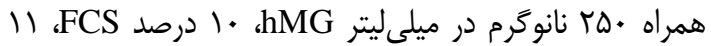

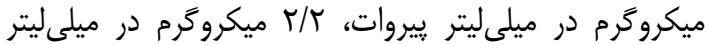

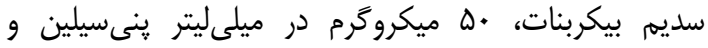

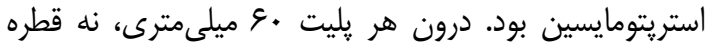

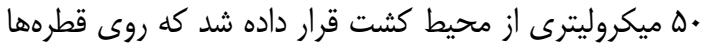

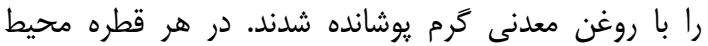

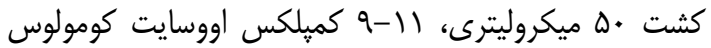

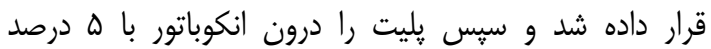

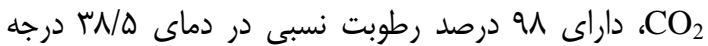

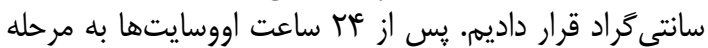

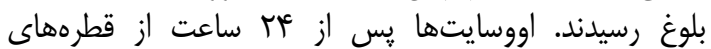

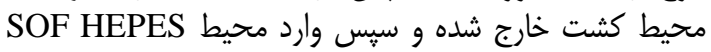

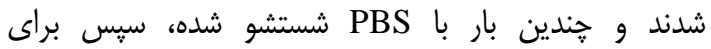

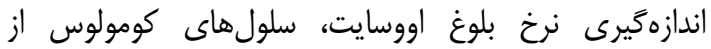

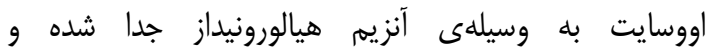

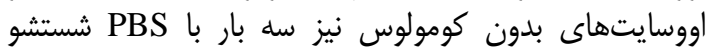

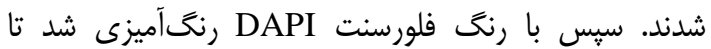
براساس ديدن جسم قطبى، نرخ اووسايتهايى كه به به مرحله

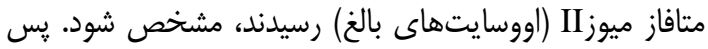

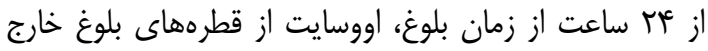

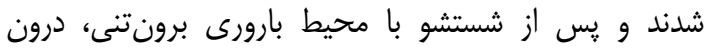

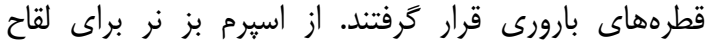

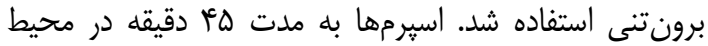

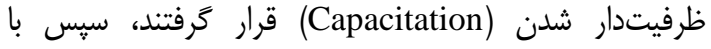
تكنيك Swim Up، اسيرمهاى بارور براى لقاح برونتيتى جدائ

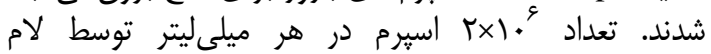

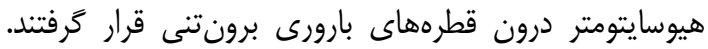

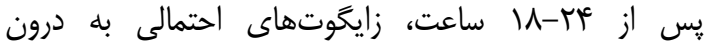

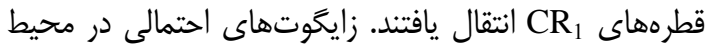
كشت برونتنى رويان كه درصد

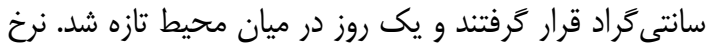

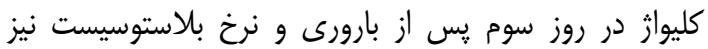

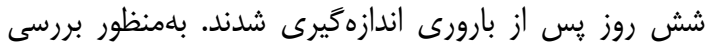

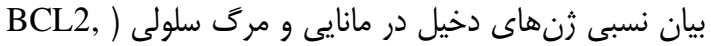
BAX, CASPASE3 اووسايت بالغ شده داراى جسم قطبى استفاده شد. از كيت و و بر مبناى دستورالعمل شركت (RNeasy Micro Kit) سازنده (QIAGEN)، جداسازى RNA صورت گرفت. QuantiTec Reves Transcription (QIAGEN, كيت جنازيت (205311 و براساس گيروتكل مربوطه، cDNA ساخته شد و 


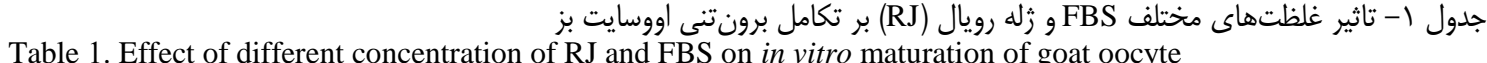

\begin{tabular}{|c|c|c|}
\hline درصد تكامل برونتى & شمار اووسايت & تيمارها \\
\hline$V \backslash / \mu^{c}$ & life & شاهد (•ا درصد FBS) \\
\hline$V \varepsilon / \Delta \varepsilon^{c}$ & lar & RJ درصد FBS + F/D ميلى گرم بر ميلى ليتر \\
\hline$V T / V \varphi^{c}$ & $1+1$ & 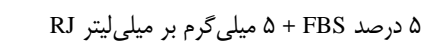 \\
\hline$\Lambda \leftarrow / s \Lambda^{b}$ & IFA & 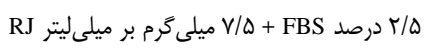 \\
\hline $91 / \sim \Delta^{a}$ & lar & RJ ا ميلى گرم بر ميلىليتر I. \\
\hline
\end{tabular}

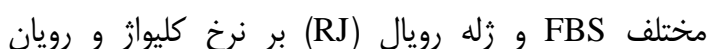

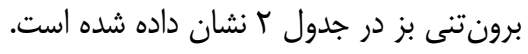

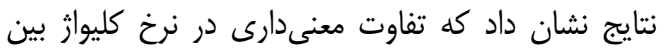

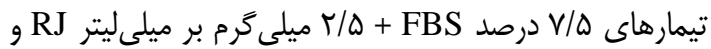

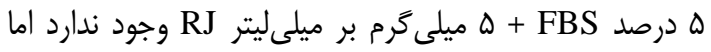
اين دو تيمار نسبت به تيمار شاهد تفاوت دارئ مارند.

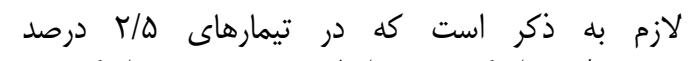
ميلى V/D + FBS

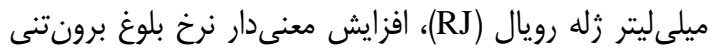

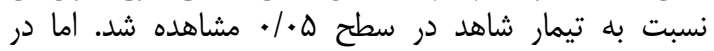

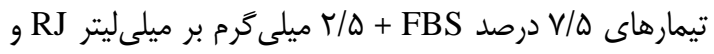

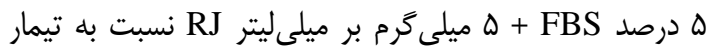

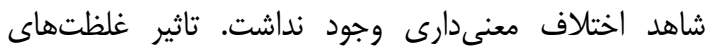

جدول r- تاثير غلظتهاى مختلف FBS و زله رويال (RJ) بر نرخ تهيه تسهيم و رويان برونتنى بز Table 2. Effect of different concentration of RJ and FBS on cleavage rate and in vitro goat embryo

\begin{tabular}{|c|c|c|c|}
\hline درصد بلاستوسيست (تعداد) & درصد كليواز (تعداد) & شمار اووسايت & 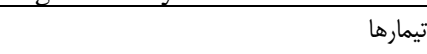 \\
\hline$(K F) Y I / K^{C} T^{C}$ & $(V \cdot) \& r / \Delta^{\mathrm{d}}$ & $11 \%$ & شاهد (•( درصد FBS) \\
\hline$(r \Lambda) r \Delta / q r^{b}$ & $(V Y) \subseteq V / \Delta q^{C}$ & $1 \cdot 1$ & RJ درصد V/D + FBS ميلى گرم بر ميلى ليتر \\
\hline$(T \Lambda) T \Psi / \Delta \xi^{b}$ & $(V \Delta) \varepsilon \Delta / V \Lambda^{c}$ & 114 & ه درصد FBS + D ميلى كرم بر ميلى ليتر RJ \\
\hline (rT) $Y N / \Lambda T^{\mathrm{a}}$ & $(\Lambda \Delta) \vee \varepsilon / \Delta V^{b}$ & 111 & RJ ميلى \\
\hline$(r r) r \cdot / \Lambda \Lambda^{a}$ & $(\wedge q) \wedge r / r^{a}$ & 1.9 & RJ ا ميلى كرم بر ميلى ليتر. \\
\hline
\end{tabular}

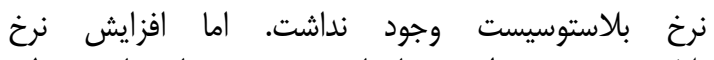

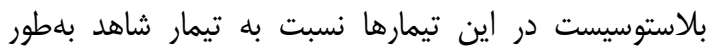

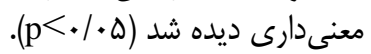

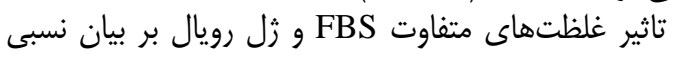

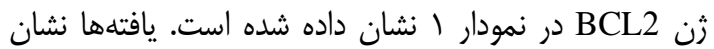

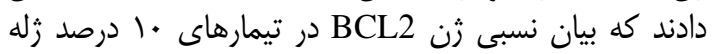

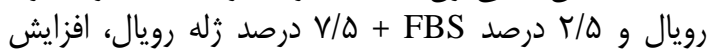

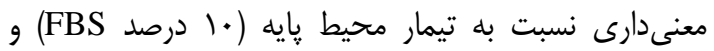
ساير تيمارهاى آزمايشى داشته است.

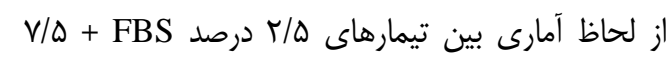
معنىدارى ميلى

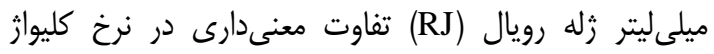

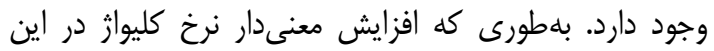

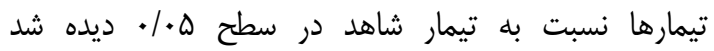

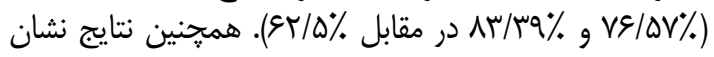

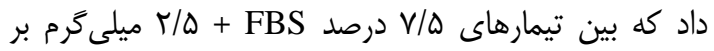

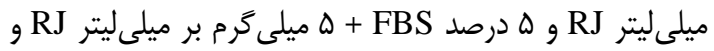
همين طور

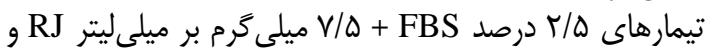

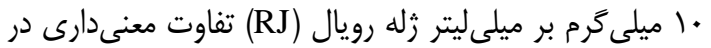




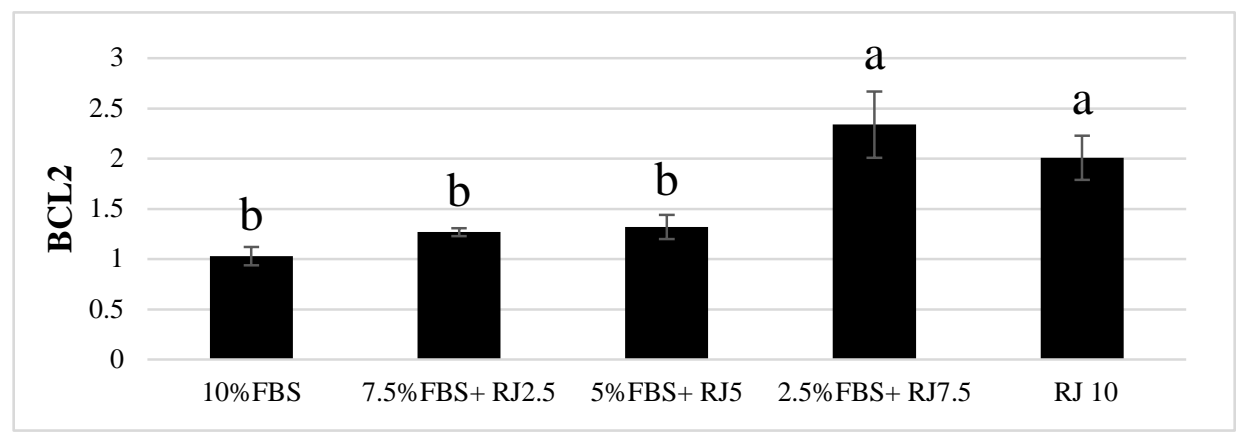

شكل ا- بيان نسبى زن BCL2 در پاسخ به غلظتهاى متفاوت FBS و زله رويال در محيط تكامل اووسايت بز. حروف نامشابه

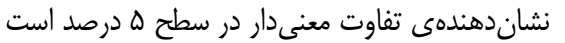

Figure 1. The relative gene expressions of BCL2 in response to different concentrations of RJ and FBS in in vitro goat maturation media. Bars with uncommon superscripts are different $(\mathrm{P}<0.05)$

نسبى ثن BAX شده است. از لحاظ آمارى تفاوتى در بيان

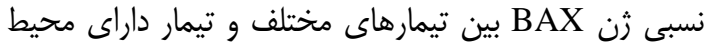
קايه (• (1 درصد FBS) مشاهده نشده است.

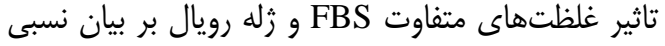

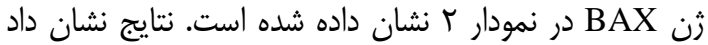

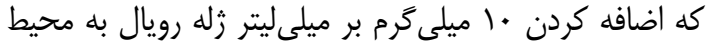

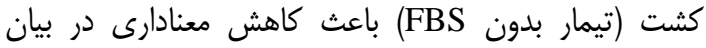

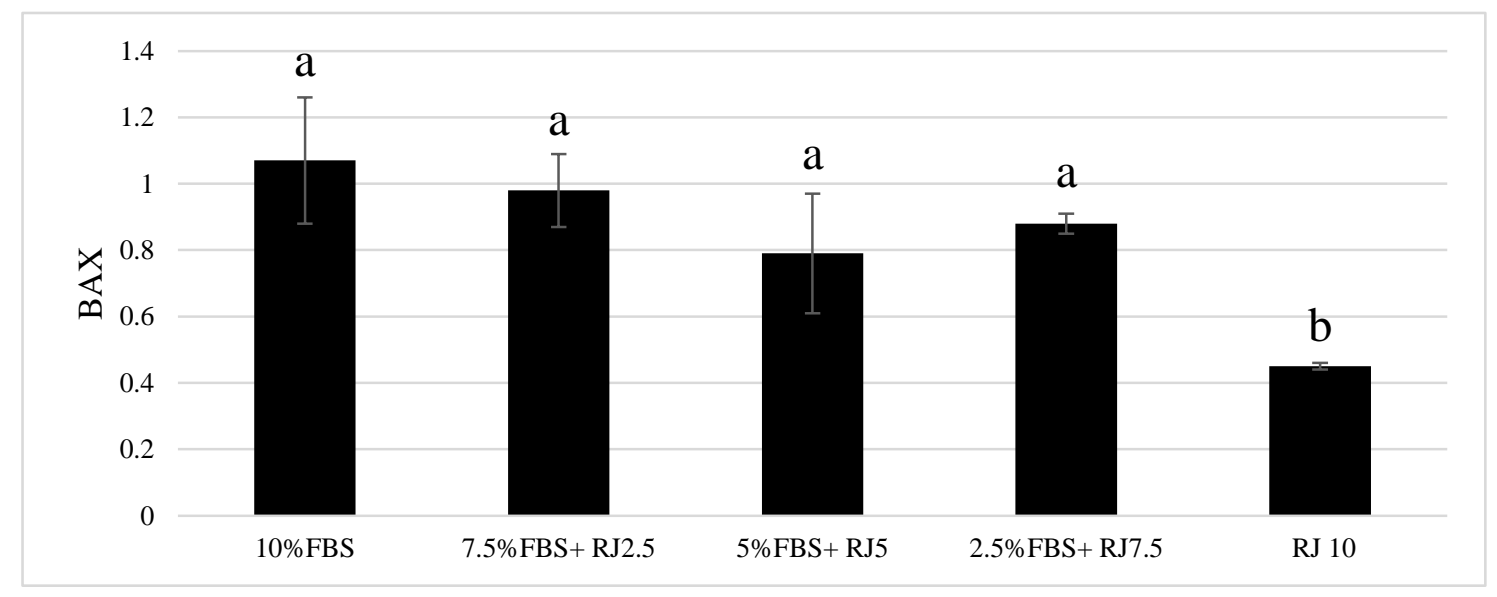

شكل r- بيان نسبى ثن BAX در پاسخ به غلظتهاى متفاوت FBS و زله رويال در توليد رويان برون تنى بز. حروف نامشابه نشان دهندهى

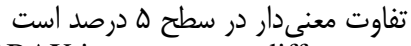

Figure 2. The relative gene expressions of BAX in response to different concentrations of RJ and FBS in in vitro goat maturation media. Bars with uncommon superscripts are different $(\mathrm{p}<0.05)$

تيمار • • ميلى

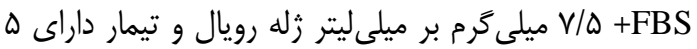

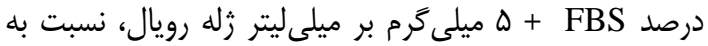
تيمار •1 درصد FBS دره است.
نسبت بيان نسبى BCL2/BAX در پاسخ به غلظتهان

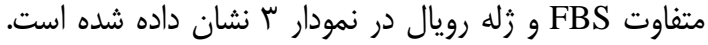

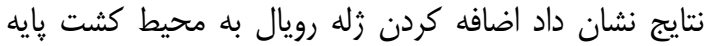
باعث افزايش معنىدارى در نسبت بيان BCL2/BAX در 


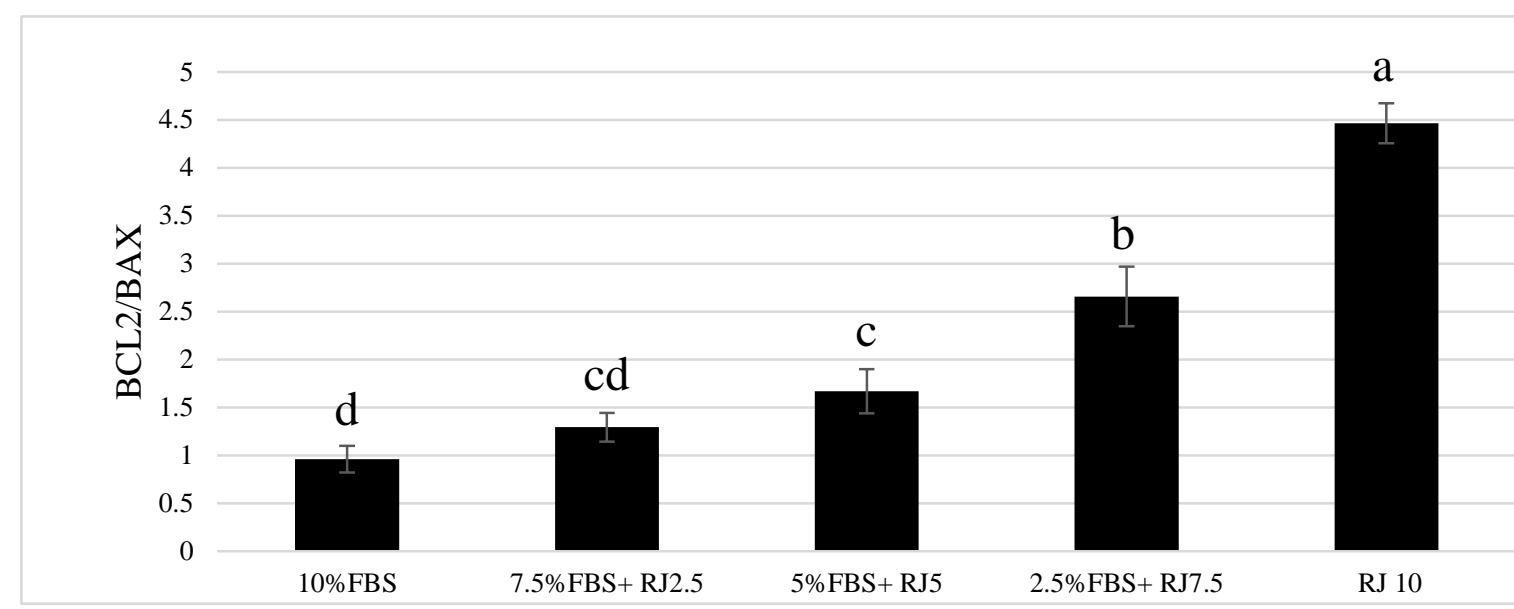

شكل س- نسبت بيان BCL2/BAX در ياسخ به غلظتهاى متفاوت FBS و زله رويال در توليد رويان برون تنى بز. حروف نامشابه نشاندهندهى تفاوت معنى دار در سطح ه در مد مد است

Figure 3. The relative gene expressions of BCL2/BAX in response to different concentrations of RJ and FBS in in vitro goat maturation media. Bars with uncommon superscripts are different $(\mathrm{p}<0.05)$

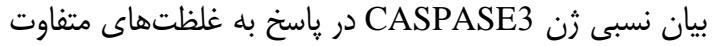
FBS

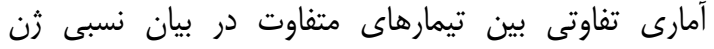
CASPASE3

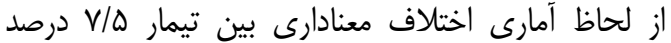
1. ميلى م/D + FBS

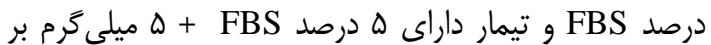
ميلى ليتر زله رويال ديده نشد.

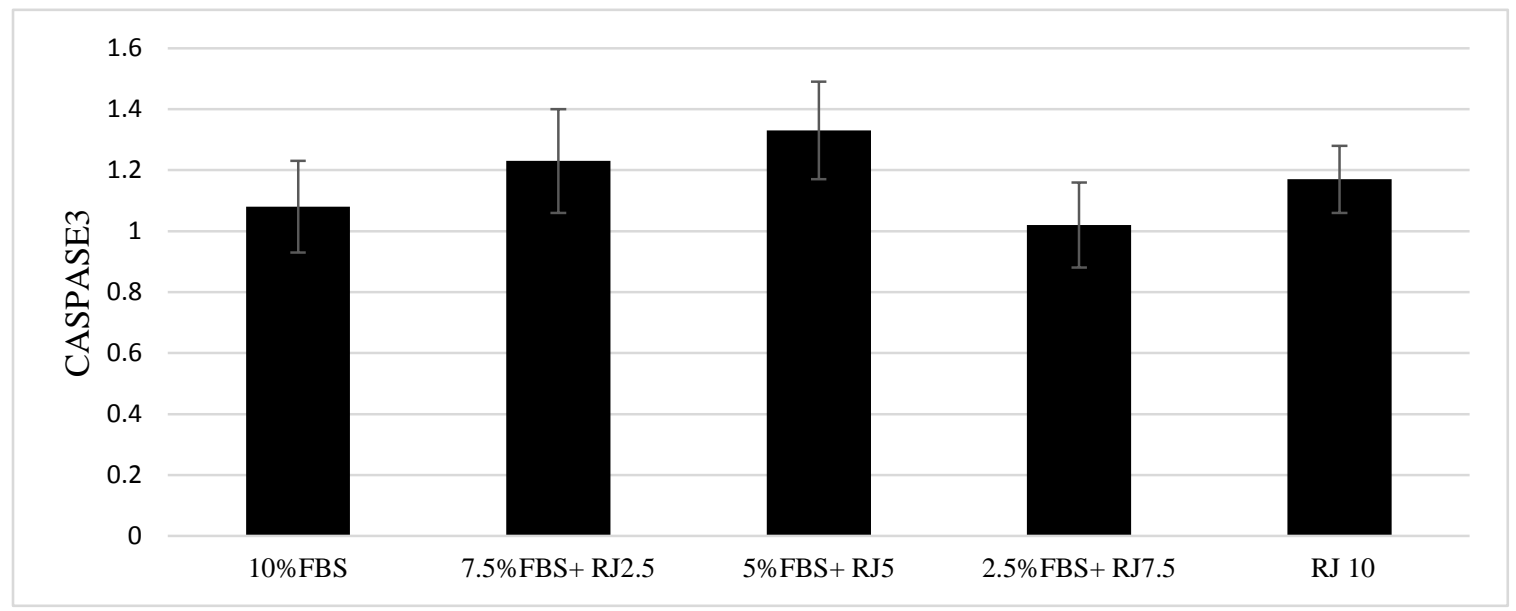

شكل זٔ- بيان نسبى زن CASPASE3 در پاسخ به غلظتهاى متفاوت FBS و زله رويال در توليد رويان برون تنى بز

Figure 4. The relative gene expressions of CASPASE3 in response to different concentrations of RJ and FBS in in vitro goat maturation media

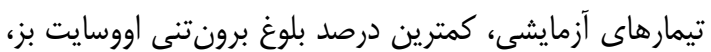

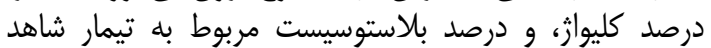

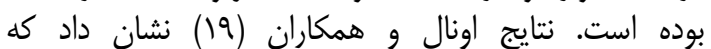

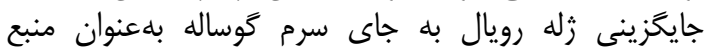

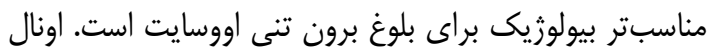

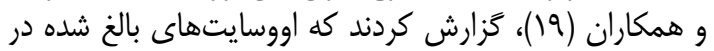

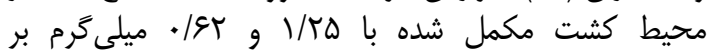

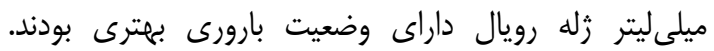

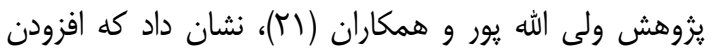
زله رويال به محيط كشت برون تنى اووسايت به طهان طور الهرد
در اين يزوهش تاثير غلظتهاى متفاوت FBS و زلهات

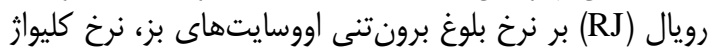

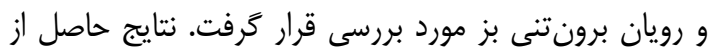

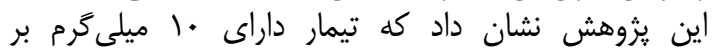

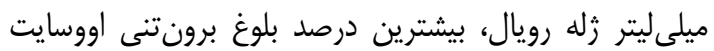

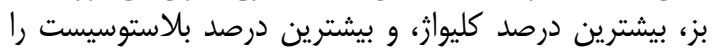

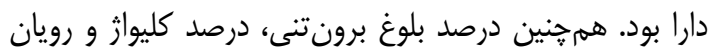

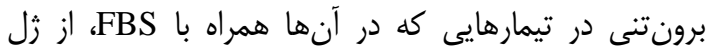

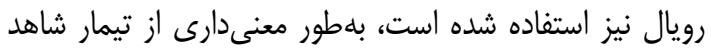
(محيط קِيه) بيشتر بوده است، بلهطوريكه در بين إن تمام 


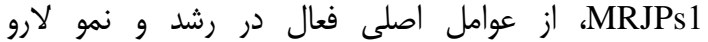

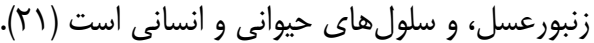

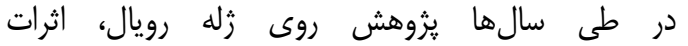

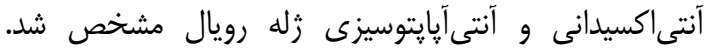

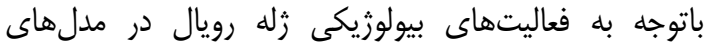

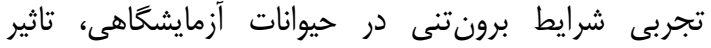

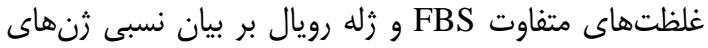
روبان مCL2 رويان برونتى بز نيز بررسى شد.

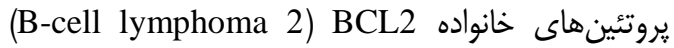

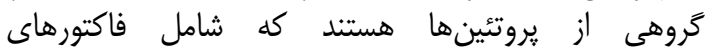

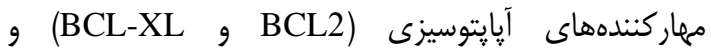

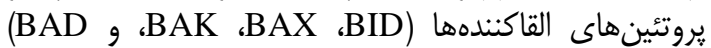

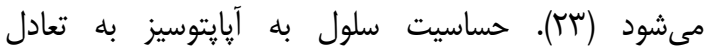

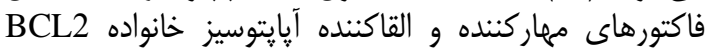

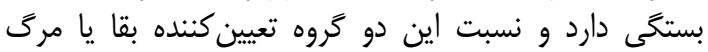

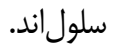

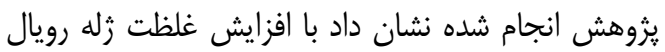

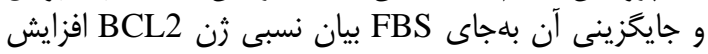

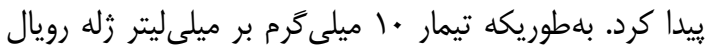
و تيمار لم/ه درصد

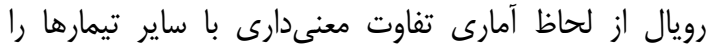

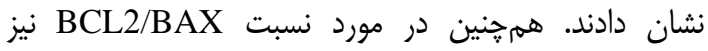

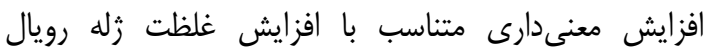

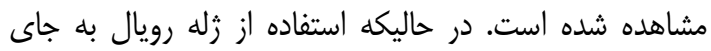

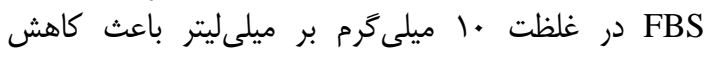

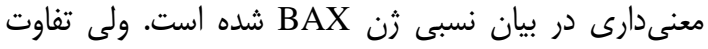

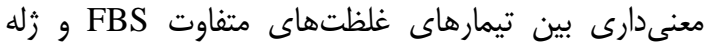

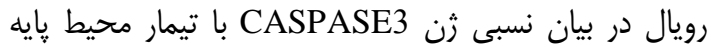

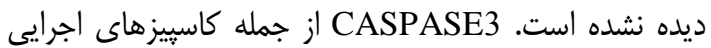

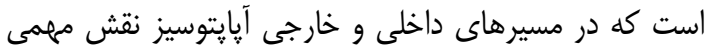

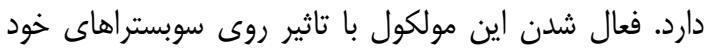

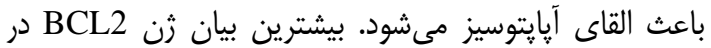

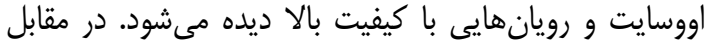

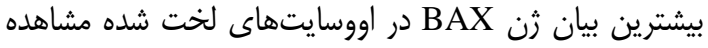

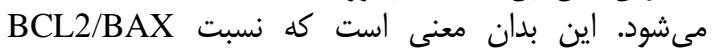

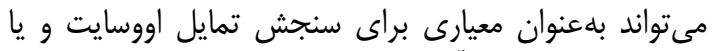

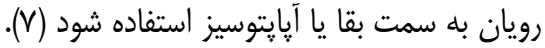

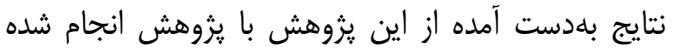

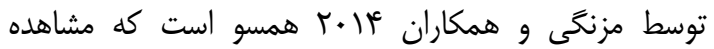

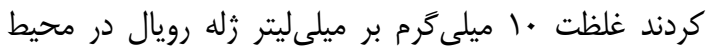

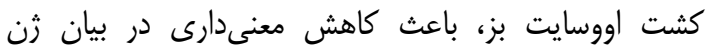

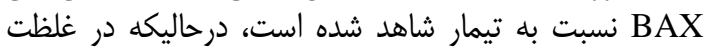

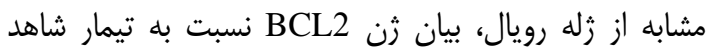

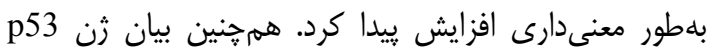

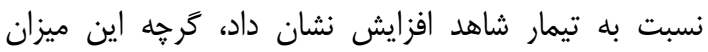

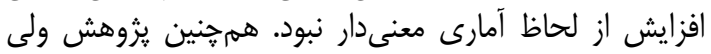

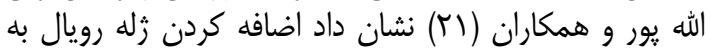

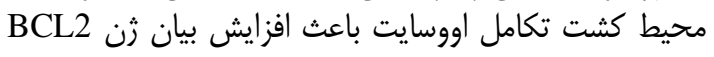

جشمخيرى نرخ بلوغ اووسايت گوسفندهاى دالاق را افزايش

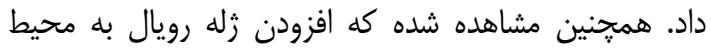

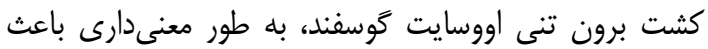

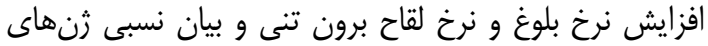

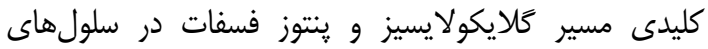

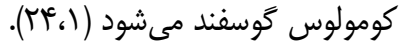

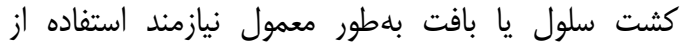

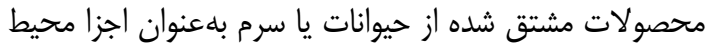

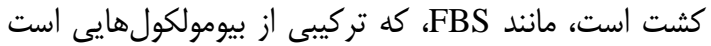

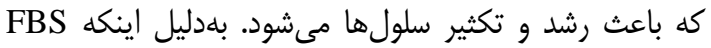

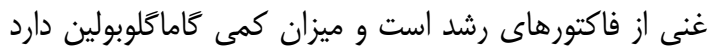

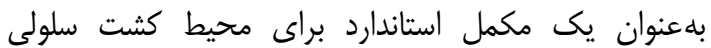

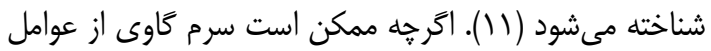

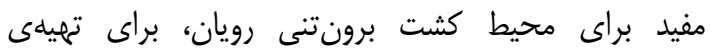

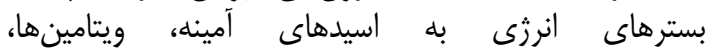

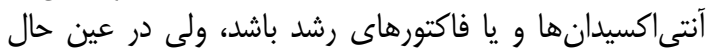

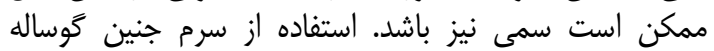
(FCS)

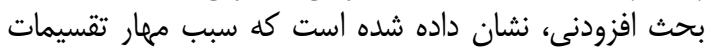

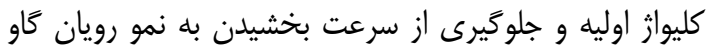

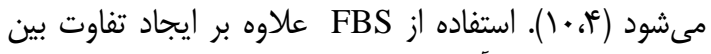

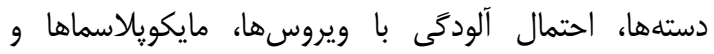

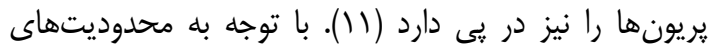

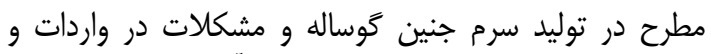

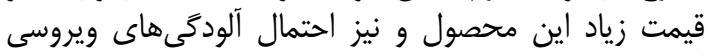

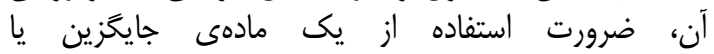

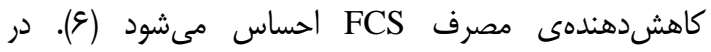

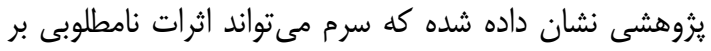

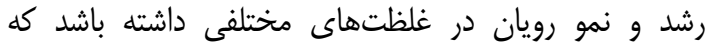

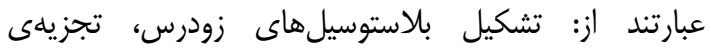

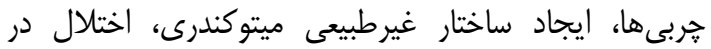

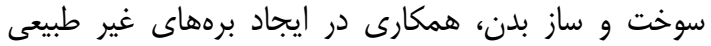

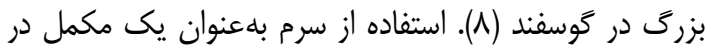

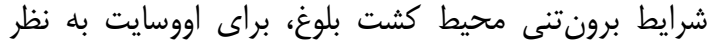

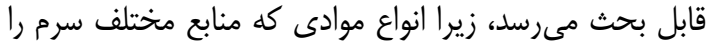

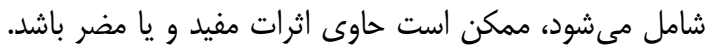

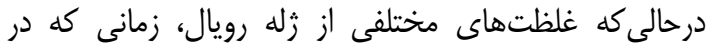

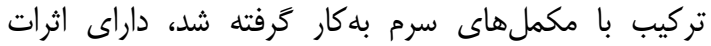
مفيدى روى بلوغ آزمايشكاهى دارد دارد

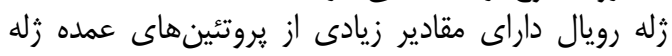

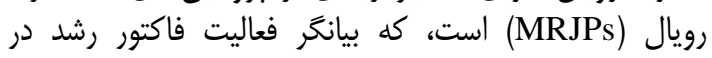

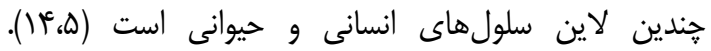

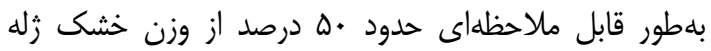

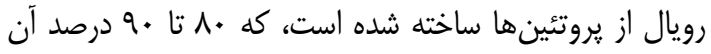

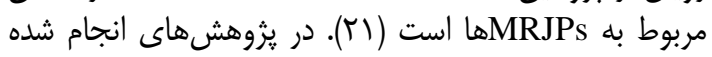

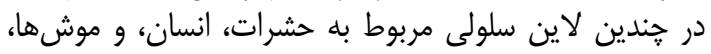

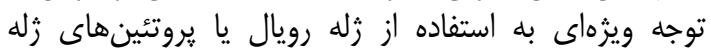

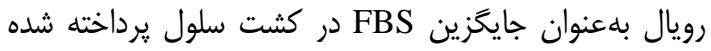

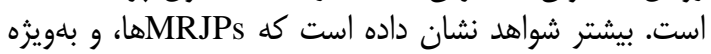


و در نهايت رويانهاى ضعيفترى مىشود (19). از آنجا كه BCL2

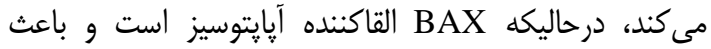

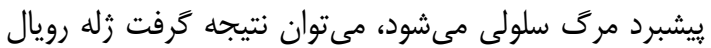

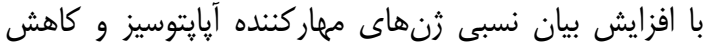

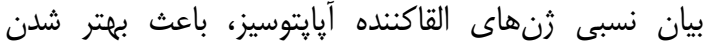
شرايط توليد برونتنى رويان بز شده است است.

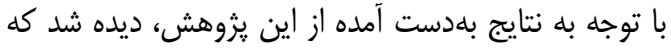

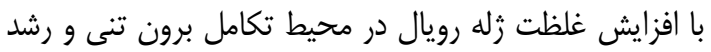

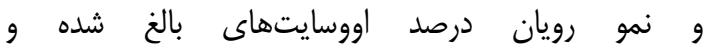

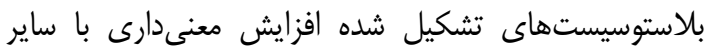

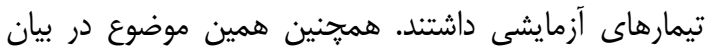

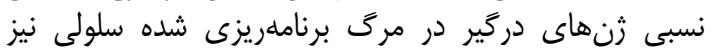

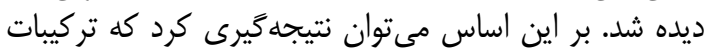

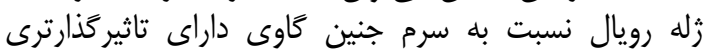

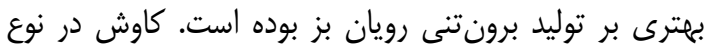

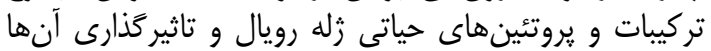

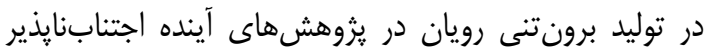

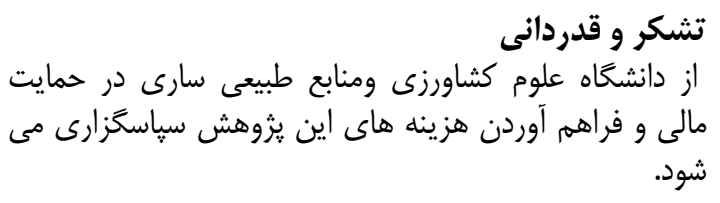

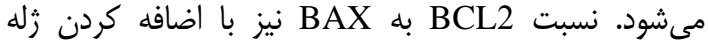

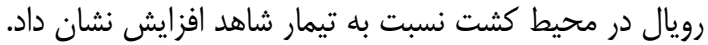

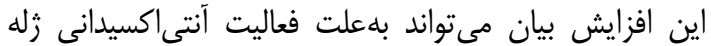

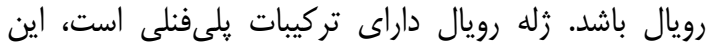

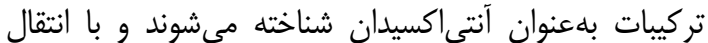

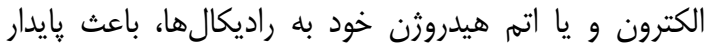

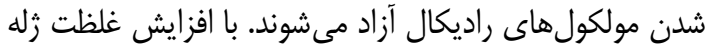

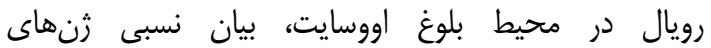

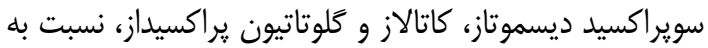

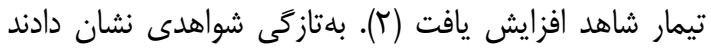

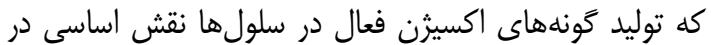

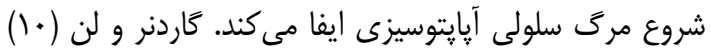

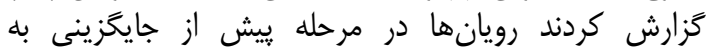

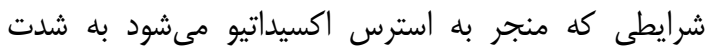

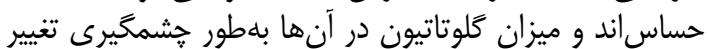

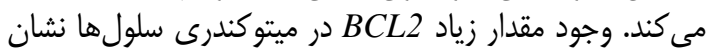

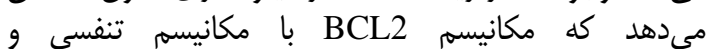
واكنشهاى اكسيداسيون / احيا مرتبط است.

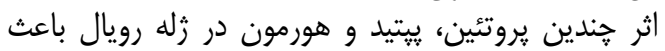

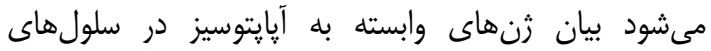

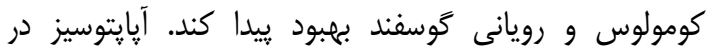

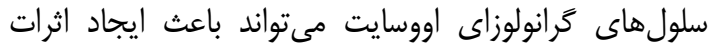

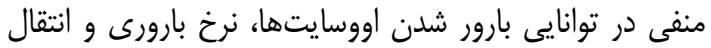

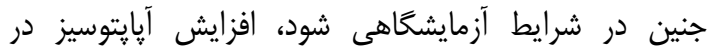
سلولهاى كرانولوزا باعث توليد اووسايتهايى با كيفيت كمتر آنرائر

منابع

1. Eshtiyaghi, M., H. Deldar, Z. Ansari Pisaraie and B. Shohreh. 2014. Effect of royal jelly on glucose metabolism in in vitro maturation and fertilization of sheep oocyte: glycolysis and penthose phosphate pathway. $6^{\text {th }}$ Iranian Animal Science Congress, Tabriz, Iran, 1-4.

2. Mohamadi, S., H. Deldar, Z. Ansari Pisaraie and B. Shohreh. 2016. Effect of royal jelly on genes encoding antioxidant enzymes in in vitro embryo production of goat. Animal Production, 18: 867-876.

3. Valioallahpor Amiri, M., H. Deldar and Z. Ansari pisaraie. 2012. Role pf royal jelly on in vitro maturation of sheep oocyte. International congress on reservation of genetic resources of Zel and Dalagh sheep. Gonbad, Iran, 527-531.

4. Bavister, B.D. 1995. Culture of preimplantation embryos: facts and artifacts. Human Reproduction Update, 1: $91-148$.

5. Chen, D., X.X. Xin, H.C. Qian, Z.Y. Yu and L.R. Shen. 2016. Evaluation of the major royal jelly proteins as an alternative to fetal bovine serum in culturing human cell lines. Journal of Zhejiang UniversitySCIENCE B (Biomedicine \& Biotechnology), 17(6): 476-483.

6. Fakhr, M., M. Mirzaei, A. Rafei, S. Armat and M. Mojtahedian. 2012. Comparative evaluation of hydatid cyst fluid and fetal bovine serum (fbs) in culture medium of rat fibroblast cells. Journal of Mazandaran University of Medical Sciences, 22: 222-230.

7. Gaddiner, C. and D.J. Reed. 1994. Status of glutathione during oxidant-induced oxidative stress in the preimplantation mouse embryo. Biology of Reproduction, 51: 1307-1314.

8. Gardner, D.K. 1994. Mammalian embryo culture in the absence of serum or somatic cell support. Cell Biology International, 18: 1163-1179.

9. Gardner, D.K. 1999. Development of serum-free culture systems for the ruminant embryo and subsequent assessment of embryo viability.In: Proceedings 5th International Symposium on Reproduction in Domestic Ruminants, pp: 461-475.

10. Gardner, D.K. and M. Lane. 1997. Culture and selection of viable blastocysts: a feasible proposition for human IVF. Human Reproduction Update, 3: 367-382.

11. Gstraunthaler, G. 2003. Alternatives to the use of fetal bovine serum: Serum-free cell culture. Altex., 20: 275-281.

12. Guo, H., Y. Kouzuma and M. Yonekura, 2008a. Structures and properties of antioxidative peptides derived from royal jelly protein. Food Chemistry, 113: 238-245. 
13. Inoue, T. 1986. The use and utilization of royal jelly and the evaluation of the medical efficacy of royal jelly in Japan.Proc. XXXthInternat.Congr.Apicult., Nagoya, Apimondia, 444-447.

14. Marghitaş, L.A. 2008. Produseleapicolesiprincipalelelorinsuşiriterapeutice In: Albinelesiproduselelor. Ceres, Bucharest, pp: 280-378.

15. Mazangi, H.R., H. Deldar, N.E. Kashan and A. Mohammadi-Sangcheshmeh. 2014. Royal jelly treatment during oocyte maturation improves in vitro meiotic competence of goat oocytes by influencing intracellular glutathione synthesis and apoptosis gene expression. Reproduction, Fertility and Development, 27: 241.

16. Nagai, T. and R. Inoue. 2004. Preparation and the functional properties of water and alkaline extract of royal jelly. Food Chemistry, 84: 181-186.

17. Nagai, T.R., R. Inoue, N. Suzuki and T. Nagashima. 2006. Antioxidant properties of enzymatic hydrolysates from royal jelly. Journal of Medicinal Food, 9: 363-367.

18. Nakahara, K., H. Saito, T. Saito, M. Ito, N. Ohta, T. Takahashi and M. Hiroi. 1997. The incidence of apoptotic bodies in membrana granulosa can predict prognosis of ova from patients participating in in vitro fertilization programs. Fertility and Sterility, 68: 312-7.

19. Onal, A.G., M. Kuran, I. Tapki, E. Sirin and O. Gorgulu. 2005. Honey bee royal jelly: an alternative source to serum for in vitro maturation of ovine oocytes. European Association for Animal Production- $56^{\text {th }}$ Annual Meeting, Uppsala, 283.

20. Schmitzová, J., J. Klaudiny, S. Albert, W. Schröder, W. Schreckengost, J. Hanes, J. Júdová and J. Simúth. 1998. A family of major royal jelly proteins of the honeybee Apis mellifera L. Cellular and Molecular Life Sciences, 54(9): 1020-1030.

21. Valiollahpoor Amiri, M., H. Deldar and Z. Asari Pirsaraei. 2015. Impact of supplementary royl jelly on in vitro maturation of sheep oocytes: genes involved in apoptosis and embryonic development. System Biology in Reproductive Medicine, 62: 31-38.

22. Zhang, G.M., C.H. Gu, Y.L. Zhan, H.Y. Sun, W.P. Qian and Z.R. Zhou. 2013. Age-associated changes in gene expression of goat oocytes. Theriogenology, 80:328-336.

23. Eshtiaghi M., H. Deldar, Z. Ansari Pirsaraei and B. Shohre. 2016. Royal jelly may improve the metabolism of glucose and redox state of ovine oocytes matured in vitro and embryonic development following in vitro fertilization, Theriogenology, 86: 2210-2221. 


\title{
The use of Royal Jelly as a Replacement of Fetal Bovine Serum in In Vitro Production of Goat Embryo with Emphasis on Apoptosis Related Genes
}

\section{Hamid Deldar}

\author{
Associate Professor of Animal Sciences Department, Sari Agricultural Sciences and Natural \\ Resources University, (Corresponding Author: hamiddeldar@gmail.com) \\ Recived: July 15, 2018

\begin{abstract}
The present study was conducted to investigate the effect of different concentrations of royal jelly as a fetal bovine serum replacement on in vitro embryo production of goat oocytes and the gene expression involved in apoptosis. In vitro maturation (IVM) of oocyte was performed in the presence of control (10\% FBS), $10 \mathrm{mg} / \mathrm{ml} \mathrm{RJ}$ (without FBS), $5 \%$ FBS and $5 \mathrm{mg} / \mathrm{ml} \mathrm{RJ}, 2.5 \%$ FBS and $7.5 \mathrm{mg} / \mathrm{ml} \mathrm{RJ,} \mathrm{7.5 \%} \mathrm{FBS} \mathrm{and} 2.5 \mathrm{mg} / \mathrm{ml}$ RJ. Nuclear statusof matured oocyte and mRNA abundance of selected genes were evaluated following $24 \mathrm{~h}$ of IVM. Following the IVM, fertilization and embryo culture were carried out in all groups and embryonic development was examined. Our data suggested that the number of oocytes at metaphase II stage, cleavage and blastocyst stage of the embryo were gradually increased followed by the dose of royal jelly gradually increased in the maturation medium. The addition of $10 \mathrm{mg} / \mathrm{ml}$ royal jelly to the maturation media was significantly increased $(\mathrm{P}<0.05)$ maturation rate $(91.35 \%)$ of goat oocyte, cleavage $(83.39 \%)$ and blastocyst formation $(30.18 \%)$ compared with the control groups $(71.31 \%, 62.50 \%$ and $21.42 \%$, respectively). By increasing of royal jelly concentrations, the mRNA transcript of the BCL2 gene was increased, while transcript abundance of BAX was significantly decreased. BCL2/BAX ratio has also been significantly increased $(\mathrm{P}<0.05)$ by increasing of royal jelly concentrations in the maturation media. However, relative gene expression of CASPAS3 gene was not significantly different between treatments. It seems that the gradual increase of royal jelly as a replacement of FBS in the maturation media had a desirable effect on oocyte maturation and the embryo development condition of caprine oocyte.
\end{abstract}

Keywords: Caprine Oocyte, Fetal Bovine Serum, In Vitro Embryo Production, Royal Jelly 